\title{
Filosofia como paixão e tarefa
}

\section{Philosophy as passion and task}

\author{
Henry Burnett \\ https://orcid.org/0000-0001-6806-8333 - E-mail: henry.burnett@unifesp.br
}

\begin{abstract}
RESUMO
Partindo da recepção da obra de Oswald de Andrade na crítica de Benedito Nunes, o texto reflete sobre os caminhos da formação em filosofia no Brasil, recuperando alguns textos-chave do filósofo paraense. Com isso, pretendemos apontar alguns caminhos abertos por sua inovadora perspectiva de reaproximar filosofia e poesia dentro de um contexto brasileiro.
\end{abstract}

Palavras-chave: Benedito Nunes. Filosofia. Oswald de Andrade.

\begin{abstract}
Starting from the reception of Oswald de Andrade's work in Benedito Nunes' critique, the text reflects on the paths of training in philosophy in Brazil, recovering some key texts by the philosopher from Pará. With this, we intend to point out some paths opened by its innovative perspective of bringing together philosophy and poetry within a Brazilian context.
\end{abstract}

Keywords: Benedito Nunes. Philosophy. Oswald de Andrade.

Gostaria de começar dizendo que sou pouco habilidoso para momentos como este, que guardam alguma solenidade mesmo quando estamos entre colegas, amigos e estudantes. Apesar disso, quando recebi o convite aceitei prontamente e espero não desapontá-los com as notas que tomei para esta fala, cujo formato é de todo inédito para mim. 
A primeira dificuldade que se enfrenta quando pensamos em uma aula inaugural para um curso de filosofia é que as diversas portas de entrada e possibilidades temáticas, sem falar na sua longa história e suas centenas de autores, acabam por nos apequenar diante da responsabilidade de escolher este ou aquele autor, ou algum problema comum. No entanto, quando pensei na direção que daria a esta intervenção, algo me pareceu inescapável: o fato de que nunca foi tão importante não apenas falar de filosofia, mas defendê-la contra os fatos que assolam nossa vida social e política. Não estando eu, propriamente, dentro da área de filosofia política, e, portanto, inapto por princípio para uma boa análise conjuntural, tudo parecia apontar para o retumbante fracasso do expositor. Ainda assim, com tudo parecendo conspirar contra, pela primeira vez me senti verdadeiramente inspirado para falar aos estudantes que agora iniciam uma trajetória cujo desfecho é incerto e insondável, talvez sempre tenha sido, mas agora com um agravante de tensão nunca antes experimentado. Peço apenas que não esperem de mim alguma sugestão de reviravolta teórica ou, sobretudo, algum tipo de voto de otimismo. Ambos não estão no horizonte próximo da nossa área.

Diria, para começar, que há muitas formas de se entrar no movediço terreno onde a filosofia se assenta. Já superamos, espero, a ideia de que a porta de entrada são os fragmentos pré-socráticos, de onde partiríamos para entender a história da filosofia como uma linha contínua e rigorosamente progressiva - nada mais equivocado, como todos sabem. Eu proporia o seguinte caminho: que tentássemos reencontrar uma ligação antiga que talvez nos ajudasse nesse rito de passagem - se é que há de fato um rito necessário, na medida em que muitos de vocês já estudaram filosofia no Ensino Médio ou tem com ela algum vínculo autodidata -, ou talvez o rito seja o espanto, como preferiam os antigos. No meu caso pessoal, devo este reencontro, ou meu espanto filosófico, aos textos de Benedito Nunes, que dedicou parte significativa de sua obra para apontar caminhos de (re)aproximação entre a filosofia e a poesia, que ele considerava interditados.

Embora sua obra seja uma referência para muitos de nós, não vejo exemplos de uma assimilação de seu legado, restando o isolamento de sempre entre as duas formas seculares, com algumas notáveis exceções que não tenho espaço e tempo para lhes mostrar no detalhe. De resto não é difícil entender a descontinuidade de sua influência sobre nossos cursos de filosofia. O filósofo profissional, talvez a maioria dos que sustentam a área hoje, não acredita muito nessa conexão da filosofia com a poesia, desconfia dela, talvez por lhe parecer mais um abismo, um sem chão, leia-se: uma falta de razão, do que uma promessa teórica séria. Enfim, uma filosofia da poesia, chamemos assim, é uma ponte que esse profissional não parece querer atravessar ou sequer tomar conhecimento. Não o culpo, porque nossa área demorou muito para se consolidar no quadro do Ensino Superior nacional e não pode jogar com o próprio destino em razão de sua própria continuidade, principalmente nos dias que correm onde a filosofia e suas irmãs são ameaçadas constantemente pelos órgãos oficiais da administração federal. Falo, obviamente, de uma questão de ordem pragmática, que nos leva à beira da paranoia quando pensamos que a filosofia e as disciplinas humanísticas podem um dia ser banidas dos currículos oficiais.

Mesmo assim quero lembrar que a filosofia, como a poesia, não se expressa apenas em tratados filosóficos e poemas; ambas podem surgir fora do espaço destinado aos mais aptos ao filosofar e ao poetar. Essa revelação espantosa manifesta através da filosofia ou da poesia pode, entretanto, ser desperdiçada com facilidade, pode até mesmo não ser percebida por quem se depara com ela ao longo da vida. Arrisco dizer que essa revelação é um privilégio de poucos, o que pode gerar o equívoco de pensar que só o filósofo e o especialista a detém.

Ocorre que, muitas vezes, o próprio filósofo não passa de um profissional tecnicamente bem treinado, passando muito longe daquela possível revelação, que também poderíamos 
chamar - tomando de empréstimo o título da canção homônima de Chico César - de um estado de poesia, na falta de nome melhor, algo que, temo dizer, a leitura de um texto ou de um poema ainda possa efetivamente causar em nós, e que, desconfio, gradativamente vem se perdendo. Esta seria uma das possíveis ligações entre a filosofia e a poesia, o momento em que nos vemos transportados para dentro de um conteúdo de verdade oposto aos saberes consolidados; onde podemos jogar racionalmente com a força do mito sem temer conclusões e arremates, onde podemos, por fim, pensar em perspectiva, como ensinou Nietzsche.

Mas não pensem que esta sugestão é aleatória ou que ela tende ao abstrato ou ao delírio catártico. Quando Benedito Nunes formulou essa aproximação, ele o fez amparado em exemplos colhidos de uma tradição doméstica muito próxima de nós: o modernismo de 1922, ou, mais especificamente a obra de Oswald de Andrade, esta, sem dúvida, foi uma de suas maiores transgressões no campo da filosofia da arte brasileira e da qual faço aqui, a partir de agora, um resumo.

Ao lado de livros sobre Heidegger (Passagem para o poético), especialidade do mestre belenense, Benedito Nunes escreveu estudos referenciais sobre Clarice Lispector ( $O$ drama da linguagem), Guimarães Rosa (A Rosa o que é de Rosa) e João Cabral de Melo Neto (João Cabral. A máquina do poema), sem falar nos artigos sobre Machado de Assis e seus estudos sobre poetas próximos dele, como o paraense Max Martins. Apesar desse generoso leque, foi estudando Oswald de Andrade que Benedito Nunes foi mais fundo no que poderíamos chamar licenciosamente de uma filosofia do modernismo. Tomo aqui apenas dois exemplos: o pequeno volume da editora Perspectiva, Oswald Canibal (de 1979) e o texto de apresentação para um dos volumes das obras completas de Oswald, intitulado "A antropofagia ao alcance de todos". Em ambos, encontramos uma chave de interpretação até então inédita sobre o autor do Manifesto antropófago. Comecemos por uma passagem marcante do segundo texto:

Nenhuma exposição do conteúdo do Manifesto Antropófago, que é o avesso do discurso lógico, pode compensar a falta das imagens e dos trocadilhos que nos dá o seu texto, cheio de intuições penetrantes. Respeitando-Ihe a flexibilidade, o tom apologético, a alusividade [tendendo ao alegórico, $\mathrm{HB}$ ] e o caráter doutrinário, distinguimos nele, para efeito de análise, os três planos seguintes: o da simbólica da repressão ou da crítica da cultura; o históricopolítico da revolução caraíba; e o filosófico, das ideias metafísicas (NUNES, 2011, p. 23).

Lido ainda hoje penso que pode causar alguma estranheza entre os filósofos esse conteúdo do Manifesto antropófago, principalmente o que Benedito Nunes chama de filosófico. Atribuir "ideias metafísicas" ao poeta que não pôde prestar as provas do concurso para a cátedra de filosofia da USP, porque não tinha graduação na área, não é apenas um motivo para boas risadas, talvez seja uma anedota que acaba por dizer alguma coisa sobre nós e nossos cursos - mas este não é meu assunto principal, isto é, a querela entre filosofia e história da filosofia brasileiras, nível máximo de nossa discussão meta-filosófica. Gostaria de seguir na rota do nosso comentador, a quem presto aqui, vale dizer, uma modesta homenagem.

Se há, de fato, estranheza na aproximação entre Oswald e um programa filosófico isso se deve a um dado simples: Oswald de Andrade não é lido na maioria dos cursos de filosofia, o que dispensa comentários. Sabendo disso, imagino que Benedito Nunes tenha sido propositalmente mais específico na sua explicitação, como na passagem abaixo.

Oswald de Andrade tirou do capítulo XXXI dos Essais de Montaigne a própria ideia da vida primitiva. Costumes sãos quanto à liberdade matrimonial e à propriedade comum da terra, 0 gosto do ócio e o prazer da dança, virtudes naturais que a "ingenuidade originária" inspirava, instituições sóbrias e sábias que a Platão fariam inveja, formam o retrato que o humanista traçou da sociedade selvagem, equilibrada e feliz, incomparavelmente superior à dos 
civilizados, não obstante a antropofagia, ato de vindita menos bárbaro do que a crueldade com que os europeus, incapazes de comer um homem morto, torturam e estraçalham um corpo humano vivo, "sob pretexto de piedade e de religião" (NUNES, 2011, p. 27).

Notemos que a estratégia é bem amparada em um empréstimo de legitimidade, firmado através da linhagem que faz recuar o modernista até Montaigne, um autor clássico; pode ser uma coincidência, mas devemos lembrar que esta filosofia brasileira de corte modernista, ao se ver espelhada no inventor do ensaio filosófico moderno, Montaigne, junta várias pontas, de Nietzsche a Adorno, de Deleuze a Agamben, e o mais importante, acaba por ser identificada a um traço singular da filosofia contemporânea mais avançada: o ensaio filosófico. Tendo ou não pensado nisso, no que duvido, o crítico deixa entrever uma grata vinculação, que, a bem da verdade, ele não inventou, mas detectou nos textos de Oswald, ou seja, suas ramificações eruditas. Ainda no texto "A antropofagia ao alcance de todos", ele mostra qual seria uma das fontes filosóficas do nosso modernista:

Oswald, generalizando indevidamente a antropofagia ritual (...) ligou essa purgação do primitivo à origem da saúde moral do Raubentier nietzschiano, do homem como animal de presa que, segundo a imagem digestiva empregada por Nietzsche em A genealogia da moral, assimila e digere, sem resquício de ressentimento ou de consciência culposa espúria, os conflitos interiores e as resistências do mundo exterior (NUNES, 2011, p. 28).

Devemos notar, entretanto, que não se trata de uma assimilação passiva e unilateral da crítica de Nietzsche no interior do modernismo brasileiro. Por isso é importante que formemos o quadro completo, que nos ajuda a entender o rigor da aproximação e os fundamentos desse modernismo filosófico que nos escapa desde sempre, com as exceções de praxe. Não sendo o que chamamos hoje de nietzscheano - outra designação que não diz quase nada -, Benedito Nunes foi um dos primeiros comentadores no interior da cena filosófica brasileira a compreender o lugar da obra de Nietzsche no quadro mais amplo da filosofia contemporânea; enquanto muitos seguiam considerando-o um filósofo menor, Benedito afinava sua leitura com o que havia de mais avançado na Pesquisa-Nietzsche internacional, mesmo sem nunca ter pertencido a ela.

Não bastasse esse lugar que ele ocupa para todos os leitores-comentadores de Nietzsche no Brasil, ele foi ainda mais fundo ao estabelecer o paralelo entre filosofia e poesia que estamos tentando apresentar aqui em seus traços principais a partir do exemplo escolhido. Esse vínculo entre Oswald e Nietzsche - que hoje pode ser encontrado, por exemplo, na obra assinalada e muito discutida de Eduardo Viveiros de Castro, quando este se apropria do conceito nietzscheano de perspectivismo - foi indiscutivelmente antecipado pelo crítico.

O que talvez possa impressionar é que as duas leituras, de Benedito e Viveiros de Castro, em vários aspectos são próximas. Nos dois casos a questão parece menos uma tentativa de intervir no que chamaríamos de pressupostos da filosofia como disciplina universitária do que nos fazer olhar para a obra de Oswald a partir de uma revisão interna de sua importância. Claro que para Viveiros de Castro trata-se de uma revisão da antropologia como disciplina, e o que tudo isso acarreta dentro daquele âmbito, mas esse não é nosso ponto aqui. Basta reter de seu esforço a necessidade de ler a obra de Oswald a partir de um rigoroso método de análise, situando-a entre as fontes incontornáveis de um pensamento brasileiro, ou melhor, de uma filosofia brasileira, com todas as letras.

É este o ponto de contato com a crítica de Benedito Nunes. Ambos trabalham sob a égide absurda do desvelamento. Digo absurda porque estamos falando de um autor cuja obra se inscreve na origem da formação do pensamento crítico brasileiro e que consideramos co- 
nhecida e reconhecida ou pelos menos incensada há décadas; considerando a distância que separa os dois autores, Benedito e Viveiros de Castro, parece que a necessidade de lermos essa obra com mais atenção permanece um ponto cego para aqueles que retornam periodicamente a Oswald. Não pretendo neste espaço restaurar o pensamento do modernista na sua totalidade, mas acho que posso chamar a atenção para uma questão que considero com alguma seriedade. Voltemos a Benedito Nunes em uma passagem fundamental, agora de seu livro Oswald Canibal:

Dois conceitos bastaram a Oswald de Andrade para traçar a esquemática filosofia de história que expôs em sua tese de concurso, A crise da filosofia messiânica: o Matriarcado e o Patriarcado como totalidades sócio-históricas. O Matriarcado inclui determinadas relações de parentesco (o filho de direito materno) e de produção (a propriedade coletiva do solo), correspondendo a relações sociais abertas (sociedades sem classes), incompatíveis com a existência do estado. É uma forma orgânica de convivência, mais próxima da Natureza, atendendo aos valores sintetizados na atitude antropofágica - a transformação do tabu em totem, como expressão afirmativa da práxis guiada por impulsos primários, ainda não reprimidos, e que se exteriorizariam, em sua natural pujança, na antropofagia ritual das sociedades primitivas. Como essa atitude é considerada básica, Oswald de Andrade associou o Matriarcado a uma cultura antropofágica, de índole orgiástica ou dionisíaca. (NUNES, 1979, p. 59).

Notemos que a proximidade, antes considerada aqui mesmo com alguma estranheza, agora não deixa dúvidas quanto ao teor rigoroso da assimilação de parte da crítica nietzscheana para a construção de uma ideia de país; este parece ser, como para Mário de Andrade, outro modernista leitor dos alemães, muito mais que uma exegese de textos, que uma entrada no ambiente refratário da pesquisa séria, como se diz. Oswald integrava um grupo bem amplo de críticos, das mais variadas matrizes, que interrogaram a história do país querendo intervir de algum modo nela. Com certeza o pendor normativo de seu outro companheiro modernista, Mário de Andrade, está ausente no programa oswaldiano, é aí que entra Nietzsche na análise certeira de Benedito Nunes.

A leitura direta de Nietzsche por Oswald permite a este não apenas se antecipar às leituras extremadas, mas também de se permitir uma incorporação de linhas mestras daquele pensamento na sua proposta modernizante. Curiosamente, Nietzsche permite a Oswald defender o primitivismo brasileiro através de uma aceitação, sintetizada na frase paradigmática que todos já ouvimos, "a [dita] contribuição milionária de todos os erros"; esses erros, assim eu interpreto, contém muito do que, de lá até aqui, costumamos não aceitar como nossos constitutivos naturais de formação. Eu diria, para ilustrar, que a modernização do país em Mário de Andrade era procurada em modelos e exemplos da alta cultura europeia, enquanto Oswald considerava nossas mazelas a própria formação pela via do inconsciente, que deveria, no entanto, ser sempre retroalimentada pelo exterior, mas com este servindo de alimento e não de modelo a ser obedecido.

Vejam como Eduardo Viveiros de Castro retoma essa ideia ao afirmar que:

A Antropofagia Oswaldiana é a reflexão metacultural mais original produzida na América Latina até hoje. Ela joga os índios para o futuro e para o ecúmeno; não era uma teoria do nacionalismo, da volta às raízes, do indianismo. Era e é uma teoria realmente revolucionária. (...) Se Mário foi o grande inventariante da diversidade, Oswald foi o grande teórico da multiplicidade - coisa muito diferente" (epígrafe da tese de doutorado Antropofagia palimpsesto selvagem, de Ana Beatriz Sampaio Soares Azevedo, USP, 2012).

Benedito Nunes insere o programa modernista de Oswald na esteira do projeto instaurado por Nietzsche contra a modernidade, e não custa lembrar que o ataque desferido contra 
os valores estabelecidos tinha, em Nietzsche, um forte pendor antidogmático, sem falar no combativo manifesto contra a filosofia e a ciência clássica. Não penso ser casual ou ilustrativa essa aproximação dos programas nietzscheano e oswaldiano. Há no entanto uma intenção da parte do nosso crítico que nem sempre é exposta em toda a sua extensão. O problema, por assim dizer, dos dois filósofos - agora já não precisamos medir palavras para categorizar nosso modernista como tal -, tomadas as devidas proporções, é a invenção do novo. Tanto um quanto outro buscavam, ou tentavam, revigorar o espaço da cultura nos quais estavam inseridos. É desnecessário elencar as diferenças entre a Alemanha, e a Europa como um todo, no final do século XIX e o Brasil da década de 1920 em diante. Vamos então pensar um pouco sobre as semelhanças.

Enquanto Nietzsche se voltava contra a filologia, disciplina que dava o tom nas instituições alemães naquele momento, imprimindo a ideia de uma objetividade científica que deveria recobrir tudo, até mesmo a filosofia e as artes, Oswald vivia em um país recém e canhestramente desenvolvido, ainda assim de modo desigual e caótico. Se Nietzsche se opunha a uma tradição secular que remontava até Aristóteles, sem falar na Revolução Industrial plenamente estabelecida na Europa, Oswald participou do primeiro momento em que algo parecido com uma crítica, ou um pensamento brasileiro, passou a se desenvolver entre nós. Não havia nem ciência, nem filosofia, nem qualquer traço de autonomia nacional em comparação com o nacionalismo alemão, dos quais fosse preciso se livrar; era invenção, não revisão. Literalmente o modernismo procurava um país que pudesse se auto-reconhecer como tal. Tivéssemos tempo para comparar os projetos individuais de Mário e Oswald de Andrade veríamos que o modernismo podia ser tudo menos homogêneo, mas nosso foco é outro. Que país Oswald desejou forjar a partir da língua da poesia? Retorno a Benedito Nunes:

A atitude antropofágica, firmada no Manifesto de 1928, sofreu em A crise da filosofia messiânica, uma forte influência do esteticismo nietzscheano. Muito próximo do Nietzsche de $A$ origem da tragédia, para quem a existência, em sua tragicidade, torna-se um fenômeno estético, e a arte um meio de "devorar" o conteúdo trágico da vida, a antropofagia, nessa versão de 1950, é uma filosofia trágica, que incorpora a psicologia orgiástica integrante dos ritos de sacrifício, ligados às matrizes primordiais das relações religiosas entre o homem e o universo. O homem da cultura antropofágica, assumindo a dureza de Zaratustra, afirma dionisiacamente a sua vontade de poder; "devorando" o que há de trágico na existência, transforma todos os tabus em totens, isto é, em valores humanos e em obras de arte (NUNES, 1979, p. 66).

Um nietzscheano mais empedernido diria que o crítico ignorava a recepção e a PesquisaNietzsche, só isso poderia justificar uma ancoragem tão grave tomando O nascimento da tragédia como referência. Seria subestimar um grande intérprete. O que Benedito Nunes compreendeu antes de qualquer outro filósofo - a exceção é notável, me refiro a Haroldo de Campos - é que o corpus fragmentário da obra de Oswald de Andrade estava irmanado ao autor de Assim falou Zaratustra não apenas pelo estilo aforismático, poético e ferino, mas sobretudo pela coesão e pela responsabilidade. A tese de concurso A crise da filosofia messiânica é interpretada como um tratado estético, e não como uma epistemologia filosófica, sugerindo um congraçamento do país desencontrado com sua arte nova, ainda que primitiva sob todos os aspectos formais. Eis aí um grande enigma que ainda teremos de enfrentar; afinal, essa proximidade de Nietzsche com as ideias de Oswald através de uma reinterpretação dos ritos de sacrifício não mostra que, para ambos, importava menos um desenvolvimento dos aspectos formais, seja na música seja na poesia, do que um reencontro com uma certa materialidade? A resposta afirmativa permite compreender a paixão de Nietzsche pelo Sul europeu, sobretudo italiano e francês, 
como antídoto contra a arte nórdica orientada pelo wagnerismo oficialesco, mas também nos ajuda a perceber alguns pontos fundamentais da nossa querela doméstica.

Eu diria que o programa oswaldiano é lido por Benedito em duas frentes: na primeira, temos essa defesa de uma força filosófica construída a partir de espelhamentos em Montaigne e Nietzsche, entre outros, autores que o próprio Oswald elencou em entrevistas, como Sartre, Simone de Beauvoir, Camus, a lista é longa; não preciso defender a importância dessa sugestão como um convite à leitura detida de uma obra tão falada quanto pouco frequentada em nossos cursos de filosofia no Brasil. Para hoje, entretanto, outra frente mostra-se mais necessária e quase urgente: a interpretação do país a partir de Oswald.

Não considero que possamos incluir Benedito Nunes entre os leitores mais entusiastas de Nietzsche, no sentido de assumir para si aquela postura desmedida, típica na obra juvenil. Mas é justamente sobre a obra central daquele período que Bendito sustenta sua interpretação, O nascimento da tragédia. Isso dá o que pensar. Quando comenta sobre o que chama de "retorno à antropofagia", já em torno de 1950 e, portanto, bem longe da famosa Semana, ele afirma:

A Antropofagia, que transportou para o campo das ideias politicas e sociais o espírito de insurreição artística e literária do Modernismo, teve um estilo de ação - a agressividade verbal sistematizada, que revelam as descomposturas, os ataques pessoais, as frases-choque, os provérbios e fábulas, publicados nos 15 números das Revista de Antropofagia ( $2^{\text {a fase), }}$ então sob o controle exclusivo do grupo que Oswald de Andrade liderava. Afetando o desprezo dadaísta pela literatura, mas usando a literatura como instrumento de rebelião individual, à maneira dos surrealistas, os nossos antropófagos foram críticos da sociedade, da cultura e da história brasileiras. Ideologicamente, eram contra as ideologias; opunham, segundo a fórmula do Manifesto de 28, que se insurgia contra as ideias "cadaverizadas", a liberdade individual ao dogma e a existência concreta ao sistema. Em declarado conflito com os padrões de comportamento coletivo, os antropófagos chegaram ao problema político pelo ideal utópico da renovação da vida em sua totalidade (NUNES, 1979, p. 51).

Esta citação poderia, tirando a referência às vanguardas, ser aplicada sem emendas ao programa ético de Nietzsche. Que toda essa matéria seja lida a partir do filtro da arte é o ponto mais importante, porque com isso nós podemos de fato pensar não a partir de ambientes hipotéticos, mas sobre o que interessava aos nossos antropófagos em termos de criação e linguagem artísticas. A poesia de Oswald não poderia servir de exemplo melhor para ilustrar o X do problema que estamos enfrentando aqui. Sendo eu incapaz de uma rigorosa leitura interna de sua poesia, no sentido de uma análise crítico-literária, penso que não incorro em nenhum equívoco se pensarmos não sobre a poética oswaldiana isoladamente, mas sobre seus desdobramentos e influências sobre a arte brasileira ulterior. Tudo o que hoje chamamos de vanguarda nas artes brasileiras está ligada de um modo ou de outro à poesia de Oswald de Andrade e à antropofagia. Poderia mencionar os mais óbvios exemplos, como o concretismo e o tropicalismo, mas prefiro revisitar um texto de Augusto de Campos, onde a extensão da obra de Oswald é posicionada sem meio termo, ao mesmo tempo próximo da crítica de Benedito Nunes e também mais ampla nos exemplos:

Contra a cultura "messiânica", repressiva, fundada na autoridade paterna, na propriedade privada e no Estado, [Oswald] advogava a cultura "antropofágica", correspondente à sociedade matriarcal e sem classes, ou sem Estado, que deveria surgir, com o progresso tecnológico, para a devolução do homem à liberdade original, numa nova Idade de Ouro.

Conotação importante derivada do conceito de "antropofagia" oswaldiano é a ideia da "devoração cultural" das técnicas e informações dos países superdesenvolvidos, para reelaborá-las com autonomia, convertendo-as em "produto de exportação" (...). Atitude 
crítica, posta em prática por Oswald, que se alimentou da cultura europeia para gerar suas próprias e desconcertantes criações, contestadoras dessa mesma cultura.

Tudo somado, o grande pecado de Oswald parece mesmo o de ter escrito em português. Tivesse ele escrito em inglês ou francês, quem sabe até em espanhol, e sua antropofagia já teria sido entronizada na constelação de ideias de pensadores originais e inortodoxos como McLuhan, Buckminster Fuller (Utopia or Oblivion), - a utopia tecnológica - mais uma contribuição para a marcha das utopias, John Cage ("Como melhorar o mundo. Você só tornará as coisas piores") e o mais recente Norman O. Brown, que em Love's Body ressuscita os temas do canibalismo freudiano e do matriarcado de Bachofen. Pensadores da América, todos eles, por sinal. (CAMPOS, 2015, p. 153).

Augusto de Campos, com a erudição que é marca dos irmãos Campos, lança luzes sobre o programa antropofágico, mas sobretudo sobre o lugar onde devemos situar Oswald, isto é, entre os grandes inventores americanos do século XX - não por acaso, igualmente pouco frequentados quando não totalmente desconhecidos de nós. Se mobilizo tantos nomes e sugestões, não é simplesmente para chamar a atenção de vocês para um escritor brasileiro; isto seria mero ufanismo. Na verdade, é contra o ufanismo e a intolerância que se amplia a cada dia que escolhi o tema que orienta esta fala. Precisamos perceber que existem formas mais amplas de falar e pensar o Brasil que as que estão na ordem do dia, que assumir a tarefa de leitores e intérpretes hoje, como é o caso da maioria de vocês, não pode significar somente o deslumbramento intelectual que nossa disciplina carrega, em muitos casos não sem alguma empáfia, ou cumprir o receituário dos órgãos de fomento à cata de bolsas e financiamentos.

A poesia e o programa oswaldiano talvez seja apenas o pretexto que escolhi para me aproximar de outras questões, menos poéticas do que eu gostaria. Se Augusto de Campos não hesita em afirmar que "a Antropofagia, que - como disse Oswald - 'salvou o sentido do modernismo', é também a única filosofia original brasileira e, sob alguns aspectos, o mais radical dos movimentos literários que produzimos" (CAMPOS, 2015, p. 154), e se uma frase como esta deveria ser referenciada por quem faz filosofia no Brasil, sinto que o momento pede mais do que o reconhecimento desse degredado filósofo brasileiro. Talvez eu quisesse chamar a atenção para o que indiretamente pode ser necessário dizer em momentos como este, onde se espera uma fala alvissareira já que a aula inaugural originalmente era chamada de "oração de sapiência". Então o que fazer quando os saberes dizem sim mas os fatos dizem não? Defender a solidão melancólica dos bem formados na grande área das Humanidades, uma solidão que habita ou habitará cada um de vocês à medida em que suas leituras se aprofundarem? Uma condição para todos nós que nos refugiamos nas palavras tentando encontrar algo no que se segurar quando tudo em volta parece desabar. É verdade que não posso deixar aqui nenhum voto de otimismo, como disse no início, mas devo dizer que o pensamento e o exercício filosófico precisa ser assumido por vocês com um grau de responsabilidade jamais visto. Trata-se não apenas de desenvolvimento pessoal e esclarecimento, de formação e aprimoramento, de enfrentar questões teóricas e dominar conceitos; trata-se a meu ver de enfrentar a ignorância com paixão absoluta e inegociável.

\section{Referências}

CAMPOS, A. de. "Revistas Re-Vistas: Os Antropófagos". In: poesia antipoesia antropofagia \& cia. São Paulo: Companhia das Letras, 2015.

NUNES, B. "A antropofagia ao alcance de todos". In: ANDRADE, O. A utopia antropofágica. 4a ed. São Paulo: ed. Globo, 2011.

NUNES, B. Oswald canibal. São Paulo: Perspectiva, 1979. 


\section{Sobre o autor}

\section{Henry Burnett}

Professor livre-docente do Departamento de Filosofia da EFLCH/UNIFESP. Possui Graduação em Filosofia pela UFPA (Belém, 1997). Mestrado e Doutorado em Filosofia pela UNICAMP (Campinas, 2000 e 2004) com estágio na Universidade de Leipzig (Alemanha, 2003-4). Pós-Doutorado pela USP (São Paulo, 2006), pelo CESEM - Centro de Estudos de Sociologia e Estética Musical - Universidade Nova de Lisboa (Lisboa 2013-2014) e pela Universität Leipzig (2015-2016). Atua nas áreas de Filosofia e Ciências Humanas e Fundamentos e Crítica das Artes. Publicou Cinco Prefácios Para Cinco Livros Escritos: Uma Autobiografia Filosófica de Nietzsche (Belo Horizonte: Tessitura Editora, 2008); Nietzsche, Adorno e um Pouquinho de Brasil (São Paulo: Unifesp, 2011); Para Ler O Nascimento da Tragédia de Nietzsche (São Paulo, Loyola, 2012) e Para Ler O Caso Wagner de Nietzsche (São Paulo, Loyola, 2018), além de seis álbuns autorais e um DVD. É membro do Conselho Editorial da Editora PHI e das revistas Limiar, Anãnsi e Apoena. Integra o grupo de pesquisa Crítica e Modernidade (CRIM) da UNICAMP e é membro da Red Iberoamericana de Estudios Nietzscheanos (RIEN). Atualmente integra o corpo permanente de docentes dos PPG em Filosofia da UNIFESP e do PPGFIL da UFPA. Foi professor visitante na Universidade Nova de Lisboa (2013-2014) e na Universidade de Leipzig (2015-2016). Atualmente é bolsista de PQ/CNPq nível 2.

Recebido em: 27.07.2021.

Aprovado em: 02.09.2021.
Received: 27.07.2021.

Approved: 02.09.2021. 